\title{
CURRENT ACCOUNT, CONSUMPTION \\ AND CAPITAL MOBILITY: \\ AN ECONOMETRIC APPROACH
}

\section{Václava Pánková*}

\begin{abstract}
This paper is an application of the consumption-smoothing current account theory the main principles of which appeared in the 1980s and gradually broadened to describe the intertemporal dynamics of important economic processes. In open economies, the consumption-smoothing current account process is related to the consumption behaviour of households. The effect on consumption choices and the current account is derived from the premise that households adjust their consumption expenditures according to the terms of trade. The process can be treated in an optimizing framework and originally was strictly connected to the permanent income hypothesis (PIH) and no restrictions to capital mobility. Both assumptions were successively relaxed and relationships allowing incorporation of the excess sensitivity hypothesis (ESH) and not perfect capital mobility have been introduced. Transformed into a VAR model with current account and national cash flow increments as endogenous variables, relevant conclusions are drawn on the basis of Granger causality, the equivalence of the current and predicted current account and an analysis of parameters of the model. Basic relationships and solutions are summarized and an application using the economies of the Czech Republic, Slovakia and Austria follows.
\end{abstract}

Keywords: current account, permanent income hypothesis, excess sensitivity hypothesis, capital mobility, VAR model

JEL Classification: E20, F21, F32, C30

\section{Introduction}

In open economies, macroeconomic adjustments to changes are conditioned by the intertemporal choices of economic agents. The effect on consumption choices and the current account is derived from the premise that households adjust their consumption expenditures according to the terms of trade. As the terms of trade worsen, households save less to smooth their consumption path, which brings about a current account deficit. On the other hand, an increase in domestic holdings of foreign assets generates a current account surplus. An economy's current account measures changes in national indebtedness and depends on future economic trends, as well as on the current economic environment. Such a consumption-smoothing current account process relates to the consumption behaviour of households following the permanent income hypothesis (PIH) and contemporaneously no restrictions on capital mobility are assumed.

Under globalization, economies are characterized by a certain degree of mobility. To measure the degree of capital mobility, the Feldstein-Horioka (1980) hypothesis is

* Václava Pánková, University of Economics, Prague, Czech Republic (pankova@vse.cz).

Written with the support of the VŠE IGA F4/24/2014. 
often applied, namely that in conditions of perfect capital mobility, domestic savings and investment rates should be uncorrelated. Recently, the importance of including foreign direct investment (FDI) in the equation has been documented by e.g. Younas (2013).

Capital mobility is a phenomenon which can be a significant factor influencing economic growth. Nevertheless, common experience shows that capital mobility is appreciated in different ways according to the economic development of a country. Rapid capital movements across national borders substantially amplify the impact on the domestic unemployment rate. Furthermore, capital flows increase the riskiness of labour income, as shown by Azariadis and Pissarides (2004). This is why the question of the optimality of the degree of capital mobility becomes interesting.

The process of current account smoothing can be treated in an optimizing framework as originally shown by Sachs (1981). His approach characterizes the current account as an outcome of the behaviour of far-sighted, inter-temporally optimizing households and firms. He also addressed the fact that government tax and debt policy can have important effects on the level of the current account balance. As an important deficiency of his model, he noted the necessity to respect capital mobility. This aspect was taken into account by Obstfeld and Rogoff (1994).

Analyses based on strong assumptions of PIH and perfect capital mobility often fail, even when dealing with highly developed economies; in the case of G-7 countries, this is demonstrated by Gaglianone (2004). For this reason, the conditions should be relaxed in favour of the excess sensitivity hypothesis (ESH) concerning consumption, established by Flavin (1981, 1993), as well as allowing for partial capital mobility as summarized by Adler (2002). If the ESH holds true, predicted and current account values are equal. The link between current account and capital mobility was analysed by Ghosh (1995). If capital mobility is optimal, the forecast and actual current account show the same variances; PIH is an integral part of this equality. Eventual inequalities are connected with not perfect capital mobility as well as the ESH.

The application may also be broadened to include special aspects. A recent example of an interesting application is that of Arajuo et al. (2013). Resource-rich developing countries with exhaustible natural resources have to manage windfalls that may induce significant macroeconomic effects in their economies, including on external stability. During a windfall, they must decide how much to consume or save of this transitory and sizeable resource income, as well as how much to invest. In doing so, they implicitly determine the macroeconomic impact of the shocks, including the effect on the current account balance and therefore on external stability. With the significant changes in resource prices, the issue of how to manage resource windfalls has become an important topic in policy discussions of such countries. Central European economies are not endowed with rich natural resources but need to buy them from abroad to attain the results of the process described.

Once formulated, the optimization problem is solved by optimal consumption. Subsequently, the optimal current account is derived. The possibility of expressing the current account with the help of national cash flow increments is crucial for an econometric treatment. The agent's optimizing behaviour is linked to an eventual information set which helps to formulate the agent's expectations. As these expectations partially reflect the past, Granger causality characterizes the process sufficiently. A vector autoregressive (VAR) model is formulated with current account and national cash flow increments as endogenous variables. 


\section{Theoretical Background}

The current account $C A_{t}$ is defined by the following formula:

$$
C A_{t}=B_{t+1}-B_{t}=Q_{t}+r B_{t}-I_{t}-G_{t}-C_{t}=Y_{t}-I_{t}-G_{t}-C_{t},
$$

where $B_{t}$ denotes the economy's stock of net foreign claims at the beginning of period $t, Q_{t}$ is net domestic product, $I_{t}$ net investment, $G_{t}$ government consumption, $C_{t}$ private consumption and $r$ the world real interest rate, assumed to be constant; $Y_{t}$ is gross domestic product. All variables are measured as per capita information.

In Obstfeld and Rogoff (1994), the following relation is derived from Equation 1:

$$
\sum_{s=t}^{\infty}\left(\frac{1}{1+r}\right)^{s-t}\left(C_{s}+I_{s}\right)=(1+r) B_{t}+\sum_{s=t}^{\infty}\left(\frac{1}{1+r}\right)^{s-t}\left(Q_{s}-G_{s}\right)+\lim _{s \rightarrow \infty}\left(\frac{1}{1+r}\right)^{s-t} B_{s} .
$$

Equation (2) is a forward iteration of formula (1) after reformulation as $C_{t}+I_{t}=(1+r) B_{t}+Q_{t}-G_{t}$. This incorporates the idea that the current account balance is the outcome of forward-looking dynamic saving and investment decisions.

Rakovski (2009) shows the conditions under which $\lim _{s \rightarrow \infty}\left(\frac{1}{1+r}\right)^{s-t} B_{s}=0$ and formulates the following optimization problem of a representative agent maximizing utility $U_{t}$ subject to the expected value of the lifetime budget constraint, commonly used to explain the consequent econometric approach:

such that:

$$
U_{t}=E_{t}\left\{\sum_{s=t}^{\infty} \beta^{s-t} u\left(C_{t}\right)\right\} \rightarrow M A X,
$$

$$
E_{t}\left\{\sum_{s=t}^{\infty}\left(\frac{1}{1+r}\right)^{s-t}\left(C_{s}+I_{s}\right)\right\}=E_{t}\left\{(1+r) B_{t}+\sum_{s=t}^{\infty}\left(\frac{1}{1+r}\right)^{s-t}\left(Q_{s}-G_{s}\right)\right\} .
$$

Here utility function $u$ is supposed to be quadratic and $0<\beta<1$ is the time preference parameter. This refers to the intertemporal choice in a similar way as the discount rate. Subtle distinctions between these two concepts are explained by e.g. Frederick et al. (2002). Problem (3) is solved by the optimal consumption given by:

$$
C_{t}^{O}=\frac{r}{\theta}\left[B_{t}+\frac{1}{1+r} \sum_{s=t}^{\infty}\left(\frac{1}{1+r}\right)^{s-t} E_{t}\left(Q_{s}-G_{s}-I_{s}\right)\right]=\frac{r}{\theta}\left[B_{t}+\frac{1}{1+r} \sum_{s=t}^{\infty}\left(\frac{1}{1+r}\right)^{s-t} E_{t}\left(N C F_{s}\right)\right]
$$

with $\theta=\frac{\beta(1+r) r}{\beta(1+r)^{2}-1}, E_{t}$ denoting expectation at time $t$ and national cash flow as:

$$
N C F=Q-G-I \text {. }
$$

Substituting (4) into (1) after some rearrangements gives an optimal current account $C A^{O}$ as follows:

$$
C A_{t}^{O}=-\sum_{s=t}^{\infty}\left(\frac{1}{1+r}\right)^{s-t} E_{t}\left(\Delta\left(Q_{s}-G_{s}-I_{s}\right)=-\sum_{s=t}^{\infty}\left(\frac{1}{1+r}\right)^{s-t} E_{t}\left(\Delta N C F_{s}\right) .\right.
$$


According to Equation (6), the optimal current account balance tends to be positive when net cash flow is expected to fall and negative when net cash flow is expected to rise.

Using (1) and (5), the consumption increment can be expressed in terms of the current account and difference in national cash flow, thus:

$$
\Delta C_{t}=(1+r) C A_{t-1}-C A_{t}+\Delta N C F_{t} .
$$

Consumption according to (4) and (7) relates to PIH, which fails in many economies including the Czech instance. For this reason, the analyses of current account behaviour based on (4) and (7) also tend to fail.

Permanent national cash flow $N C F^{P}$ is defined as the annuity value of the sum of net foreign assets and the present discounted value of expected $N C F$. Hence,

$$
N C F_{t}^{P}=r B_{t}+\frac{r}{1+r} \sum_{s=t}^{\infty}\left(\frac{1}{1+r}\right)^{s-t} E_{t}\left(N C F_{s}\right) .
$$

Moreover, transitory national cash flow is the difference between total cash flow $N C F_{t}+r B_{t}$ and the $N C F_{t}^{P}$ :

$$
N C F_{t}^{T}+N C F_{t}+r B_{t}-N C F_{t}^{P} .
$$

According to Flavin (1993),

$$
C_{t}=\beta N C F_{t}^{P}+N C F_{t}^{P},
$$

where $\beta$ is known as the excess sensitivity parameter. When $\beta=0$, it is $C_{t}=N C F_{t}^{P}$ that proves the PIH. By including $\beta$, we address the ESH. Evidently, the PIH is a special case of the ESH.

For practical reasons (see Adler, 2002), it is useful to substitute (9) and (10) into (1). Together with (5), we obtain:

$$
C A_{t}=(1-\beta) N C F_{t}^{T} .
$$

Substituting further (8) into (9), we have:

$$
N C F_{t}^{T}=N C F_{t}-\frac{r}{1+r} \sum_{s=t}^{\infty}\left(\frac{1}{1+r}\right)^{s-t} E_{t}\left(N C F_{s}\right)
$$

and after rearranging:

$$
N C F_{t}^{T}=-\sum_{s=t+1}^{\infty}\left(\frac{1}{1+r}\right)^{s-t} E_{t}\left(\Delta N C F_{s}\right) .
$$

Instead of (11), we now have:

$$
C A_{t}=(1-\beta)\left[-\sum_{s=t+1}^{\infty}\left(\frac{1}{1+r}\right)^{s-t} E_{t}\left(\Delta N C F_{s}\right)\right],
$$

which equals (6) under the PIH, meaning $\beta=0$.

From (1), (5) and (13), we can derive:

$$
C_{t}=r B_{t}+N C F_{t}-C A_{t}=r B_{t}+N C F_{t}+(1-\beta)\left[\sum_{s=t+1}^{\infty}\left(\frac{1}{1+r}\right)^{s-t} E_{t}\left(\Delta N C F_{s}\right)\right],
$$

which again relates to the ESH. 
In the context of model (17), if the ESH should hold true, predicted and actual current account values should be equal:

$$
C \hat{A}_{t}=C A_{t}
$$

For the proof, see e.g. Adler (2002).

The concept of (15) and its history are summarized by Obstfeld and Rogoff (1994). They explain that it is based on an assumption that the model captures all the information people use to forecast future cash flow, the reason being that $C A_{t}$ captures the representative consumer's best estimate of the present value of future cash flow changes, regardless of the other information held. Originally, (15) was related to the PIH in the sense that if the PIH is true, then (15) holds. Adler (2002) shows a more general validation including the $\mathrm{ESH}$, the former $\mathrm{PIH}$ statement of which is a special case with $\beta=0$ in (13).

In addition, there is an important link between the current account and capital mobility, as analysed by Ghosh (1995) with the following result. In case of the PIH, perfect capital mobility coincides with:

$$
\operatorname{Var}\left(C \hat{A}_{t}\right)=\operatorname{Var} C A_{t}
$$

If $\operatorname{Var}\left(C \hat{A}_{t}\right)<\operatorname{Var} C A_{t}$ the current account is said to be excessively volatile and the degree of capital mobility is higher than would be perfect. If $\operatorname{Var}\left(C \hat{A}_{t}\right)>\operatorname{Var}\left(C A_{t}\right)$, lower than perfect capital mobility occurs.

The validity of (16) is accompanied by $\beta=0$. According to economic reasoning, given in detail in Adler (2002), the lower the degree of capital mobility, the higher the value of $\beta$. The limiting of the value to $\beta=0$ means that the current account is closed and actual consumption cannot be smoothed. For $0<\beta<1$, the degree of capital mobility is lower than perfect level. In the case of $\beta<0$, the degree of capital mobility is higher than optimal.

\section{Model}

The Equation (10), related to the ESH, explains $C A_{t}$, which is observable with the help of expected values of $\triangle N C F_{t}$. As the process may partially be studied by using past values, the Granger causality from $C A_{t}$ to $\triangle N C F_{t}$ gives the statistical evidence that the agent has relevant information.

To evaluate the ESH including a verification of Granger causality, we study a VAR model:

$$
\left[\begin{array}{c}
\Delta N C F_{t} \\
C A_{t}
\end{array}\right]=\left[\begin{array}{ll}
\psi_{11} & \psi_{12} \\
\psi_{21} & \psi_{22}
\end{array}\right]\left[\begin{array}{c}
\Delta N C F_{t-1} \\
C A_{t-1}
\end{array}\right]+\left[\begin{array}{l}
\mu_{\Delta N C F} \\
\mu_{C A} C S
\end{array}\right]+\left[\begin{array}{l}
u_{t 1} \\
u_{t 2}
\end{array}\right] .
$$

Based on the following considerations, the VAR model should be stationary. It can be proven by finding that $N C F_{t} \approx I(1)$; hence, $\triangle N C F_{t}$ is stationary. Then, also $C A_{t} \approx I(1)$ because it is a linear combination of $\triangle N C F_{t}$. Alternatively, we may examine the cointegration of $N C F_{t}+r B_{t} \approx I(1)$ and $C_{t} \approx I(1)$, as this indicates (1).

Model (17) is very convenient for predicting values of $C \hat{A}_{t}$. Unfortunately, to compare $C \hat{A}_{t}$ and $C A$ according to (15) or (16), a great part of time series $C A$ should be separated out; in such a case, a graphical output will provide us with basic information. Analysing economies with no long market economic history, a more cumbersome way is disposable. 
Let us define vectors $e_{1}^{\prime}=\left(\begin{array}{ll}1 & 0\end{array}\right)$ and $e_{2}^{\prime}=\left(\begin{array}{ll}0 & 1\end{array}\right)$. Rewriting (17) in the matrix form, we have:

$$
X_{t}-\mu=\Psi X_{t-1}+u_{t}
$$

and for $C A^{O}$ constructed according to (6), it is:

$$
C A_{t}^{O}-\mu_{C A^{O}}=K\left(X_{t}-\mu\right),
$$

with $K$ being a vector:

$$
K=e_{1} \frac{1}{1+r} \Psi\left(I-\frac{1}{1+r} \Psi\right)^{-1} .
$$

The path from (6) to (19) is described generally in Gaglione (2004); in our case, $\Delta N C F_{t}=e_{1}{ }^{\prime} X_{t}$ and following (18), $\Delta N C F_{t}-\mu_{\Delta N C F}=e_{1}{ }^{\prime}\left(X_{t}-\mu\right)$. Substituting into (6), after some rearrangements (19) is related.

Testing:

$$
H_{0}: C A_{t}^{O}-\mu_{C A^{O}}=C A_{t}-\mu_{C A},
$$

we examine the validity of:

$$
C A_{t}^{O}-\mu_{C A^{o}}=C A_{t}-\mu_{C A}=e_{2}^{\prime}\left(X_{t}-\mu\right) .
$$

Combining (19), (20) and (21), we have:

$$
e_{2}^{\prime}\left(X_{t}-\mu\right)=-e_{1}^{\prime} \frac{1}{1+r} \Psi\left(I-\frac{1}{1+r} \Psi\right)^{-1}\left(X_{t}-\mu\right)
$$

and after multiplying by inverse matrices of $\left(X_{t}-\mu\right)$ and $\left(I-\frac{1}{1+r} \Psi\right)^{-1}$ it is:

$$
e_{2}^{\prime}\left(I-\frac{1}{1+r} \Psi\right)=-e_{1}^{\prime} \frac{1}{1+r} \Psi .
$$

Applying the structure of matrix $\Psi$, the question of the validity of (21) changes into a check of restrictions on the elements of matrix $\Psi$. To not reject the null hypothesis, we should find:

$$
\psi_{11}=\psi_{21} \text { and } \psi_{12}=\psi_{22}-(1+r)
$$

according to the Wald test.

As derived in Gaglione (2004) and based on Flavin (1993), $K=\left[\begin{array}{ll}A & B\end{array}\right]$ with:

$$
\begin{gathered}
A=\frac{1}{C}\left[-\psi_{11}\left(1+r-\psi_{22}\right)-\psi_{12} \psi_{21}\right] \\
B=\frac{1}{C}\left[-\psi_{11} \psi_{12}-\psi_{12}\left(1+r-\psi_{11}\right)\right] \\
C=1+2 r-\psi_{22}+r^{2}-r \psi_{22}-\psi_{11}-\psi_{11} r+\psi_{11} \psi_{22}-\psi_{12} \psi_{21} .
\end{gathered}
$$

The null hypothesis corresponds to $A=0, B=1$.

Evidently, the key assumption is $C A$ Granger causes $\triangle N F A$. Otherwise, $\psi_{12}=0$; hence, $B=0$ and we reject the null hypothesis. 
Equation (22) relates to the PIH; in the case of the ESH, we use (13) to explain (7) as follows:

$$
\begin{aligned}
& (1+r) C A_{t-1}-C A_{t}+\Delta N C F_{t}= \\
& \beta \Delta N C F_{t}+(1+r) C A_{t-1}-C A_{t}+(1-\beta) \Delta N C F_{t}= \\
& \beta \Delta N C F_{t}+(1-\beta)\left[-\sum_{s=t}^{\infty}\left(\frac{1}{1+r}\right)^{s-t} E \Delta N C F_{s-1}+\sum_{s=t}^{\infty}\left(\frac{1}{1+r}\right)^{s-t} E \Delta N C F_{s}\right]= \\
& \beta \Delta N C F_{t}+(1-\beta)\left[-(1+r) \sum_{s=t-1}^{\infty}\left(\frac{1}{1+r}\right)^{s-t} E \Delta N C F_{s-1}+\sum_{s=t+1}^{\infty}\left(\frac{1}{1+r}\right)^{s-t} E \Delta N C F_{s}+\Delta N C F_{t}\right]= \\
& \beta \Delta N C F_{t}+(1-\beta)\left[\sum_{s=t+1}^{\infty}\left(\frac{1}{1+r}\right)^{s-t}\left(E_{t} \Delta N C F_{s}-E_{t} \Delta N C F_{s-1}\right)\right]
\end{aligned}
$$

with the small inaccuracy $(1-\beta) \Delta N C F_{t} \cong(1-\beta) E \Delta N C F_{t}$ (not to be supposed for $\left.s \neq t\right)$. In terms of the VAR model, the left-hand side of (23) is

$$
\begin{aligned}
& (1+r) C A_{t-1}-C A_{t}+\Delta N C F_{t}= \\
& =\left\{(1+r) e_{2}^{\prime}-e_{2}^{\prime} \Psi+e_{1}^{\prime} \Psi\right\} X_{t-1}+\left(e_{1}^{\prime}-e_{2}^{\prime}\right) \varepsilon_{t}=\left\{\left(e_{1}^{\prime}-e_{2}^{\prime}\right) \Psi+(1+r) e_{2}^{\prime}\right\} X_{t-1}+\left(e_{1}^{\prime}-e_{2}^{\prime}\right) \varepsilon_{t}
\end{aligned}
$$

while for the right hand side of (23) we have

$$
\begin{aligned}
& \beta \Delta N C F_{t}+(1-\beta)\left[-\sum_{s=t+1}^{\infty}\left(\frac{1}{1+r}\right)^{s-t}\left(E_{t} \Delta N C F_{s}-E_{t} \Delta N C F_{s-1}\right)\right]= \\
& =\beta e_{1} \Psi X_{t-1}+\beta e_{1}^{\prime} \varepsilon_{t}+(1-\beta)\left[-\sum_{s=t+1}^{\infty}\left(\frac{1}{1+r}\right)^{s-t} e_{1} \Psi^{s-t} \varepsilon_{t}\right]
\end{aligned}
$$

The evident consequence is:

$$
\left(e_{1}^{\prime}-e_{2}^{\prime}\right) \Psi+(1+r) e_{2}^{\prime}=\beta e_{1}^{\prime} \Psi
$$

and

$$
\left(e_{1}^{\prime}-e_{2}^{\prime}\right)=\beta e_{1}^{\prime}+(1-\beta)\left[-\sum_{s=t+1}^{\infty}\left(\frac{1}{1+r}\right)^{s-t} e_{1}^{\prime} \Psi^{s-t}\right] \text {. }
$$

For further details, see Adler (2002); he also gives a proof of the fact that (26) holds if and only if (27) is true. For our further analyses, (26) is essential. On both sides of (26) there are vectors. For their first elements we derive:

$$
(1-\beta) \psi_{11}=\psi_{21}
$$

and for the second element it is:

$$
(1-\beta) \psi_{12}=\psi_{22}-(1+r),
$$

as a more general version of (22). In the case of the PIH, $\beta=0$ and (28) changes into (22). Computing $\beta$ from $(1-\beta) \psi_{11}=\psi_{21}$, the other part of (28) can be used not only 
to perform the relevant Wald test but also to experiment with different values of the interest rate.

To summarize the procedure, we have to perform the following steps:

(a) Verify the stationarity of $\triangle N C F_{t}$ (the stationarity of $C A_{t}$ follows).

(b) Calculate parameters $\psi$.

(c) Check whether $C A_{t}$ Granger causes $\triangle N C F_{t}$.

(d) Calculate parameter $\beta$.

(e) Test the restrictions on parameters.

\section{Application}

Using annual data covering the period 1996-2014 (source Eurostat), the above model and method have been applied to the economies of the Czech Republic, Slovakia and Austria. The Austrian economy is included not only to enable the drawing of comparisons, but also as a tool for verification: in the case of results rating the Czech Republic and Slovakia significantly better than Austria, there is the motivation to look for reasonable explanations if not for possible errors.

The variable $C A_{t}$ was constructed according to formula (1), using gross domestic product for $Y_{t}$, gross capital formation for $I_{t}$, final consumption expenditure of general government for $G_{t}$ and final consumption expenditures of households as $C_{t}$. $C A_{t}$ values with suffixes denoting the country (A - Austria, C - the Czech Republic, S - Slovakia) are presented in Figure 1.

Figure 1 | Values of CA Variables

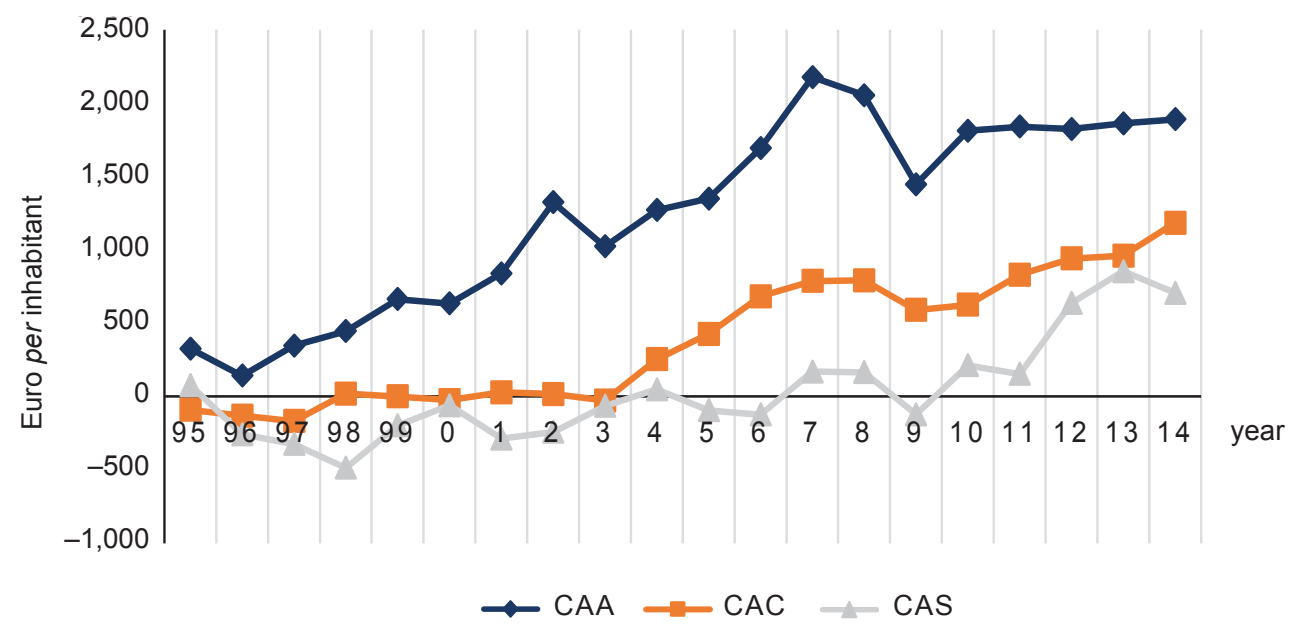

To construct $N C F_{t}$ according to (5) with $Q_{t}=Y_{t}-r B_{t}$, current transfers, receivables from the rest of the world were used for $B_{t}$. As for the interest rate, preliminary computations were performed using the average value of the world interest rate $(3.5 \%)$, LIBOR related 
to GDP (4.42\%), EMU convergence criterion bond yields (4.57\%; hereinafter referred to as EMUc). On obtaining results with no statistical significance, the reasons for this and means of improvement should be found.

First, all interest rates evinced a steep decline over the period analysed (see Figure 2 for EMUc); thus, the average value gives a very distorted picture. For this reason, the relation $Q_{t}=Y_{t}-r_{t} B_{t}$ was used for further computations, with EMUc as an interest rate value. The choice of EMUc is justified by the fact that the economies in question operate mainly in the European context.

Figure 2 | Values of EMUc

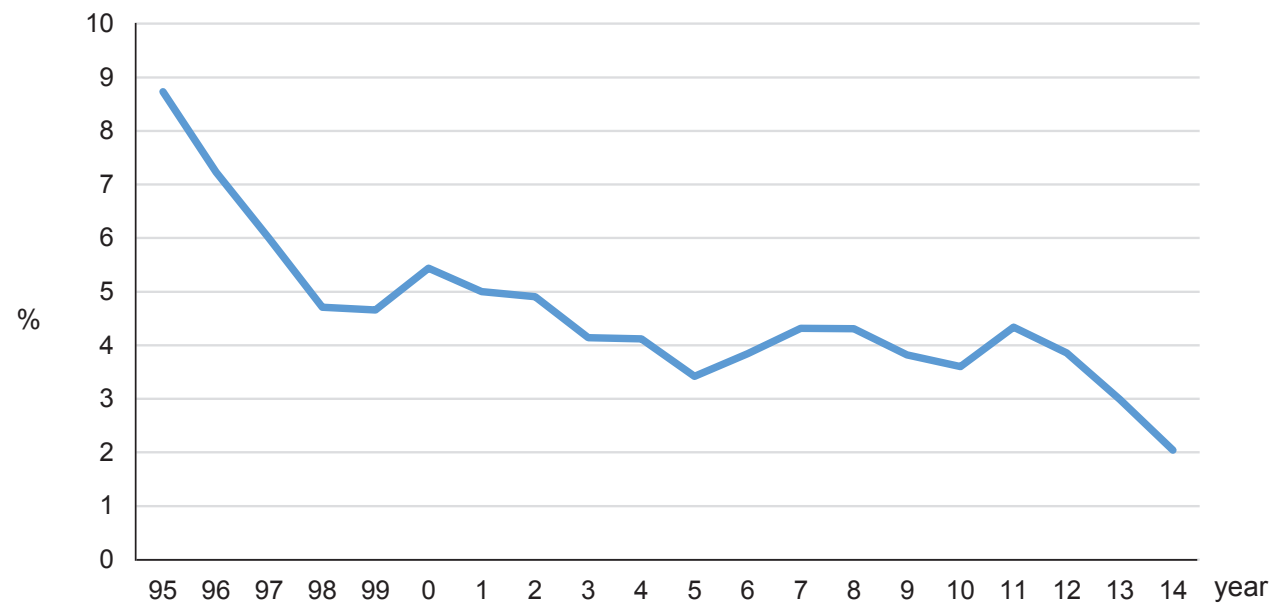

Second, $\triangle N C F_{t}$ with relevant suffixes (see Figure 3) are notably low between 2008 and 2009. As this may be understood to be a consequence of the financial crisis, the dummy variable $D$ marking this event was introduced to the model.

Figure 3 | Values of $\triangle N C F$ Variables

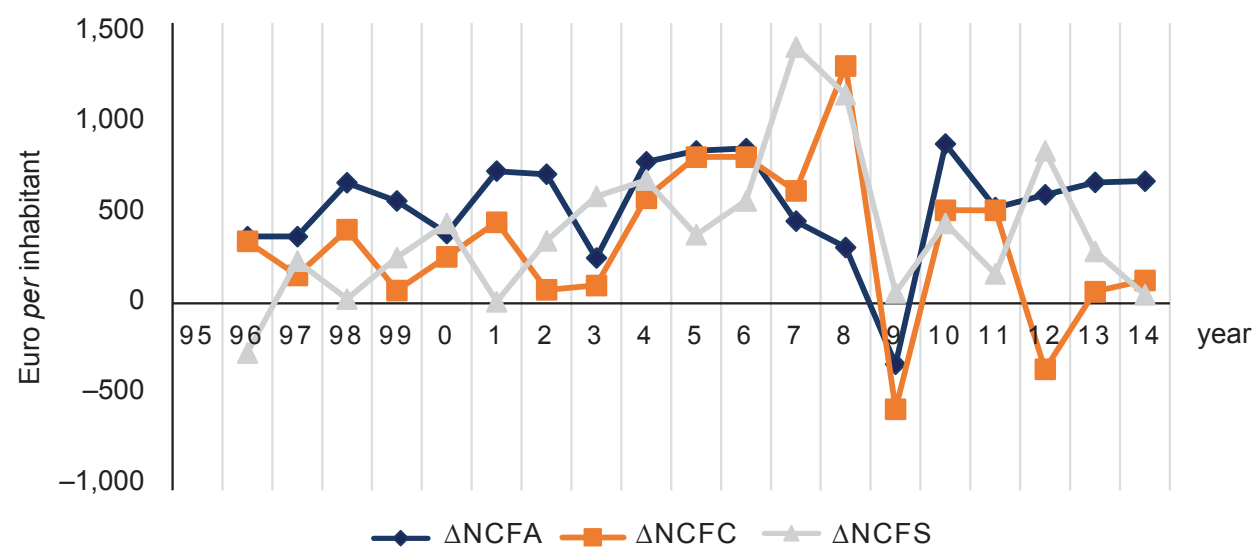


The results of the estimation of the VAR model and accompanying analyses are presented in Table 1.

Table 1 | Results of Estimation and Accompanying Analyses

\begin{tabular}{|c|c|c|c|}
\hline & Czech Republic & Slovakia & Austria \\
\hline$\Delta N C F$ stationary* & yes & yes & yes \\
\hline CA stationary* & yes & yes & yes \\
\hline$\psi_{11}$ (t-value) & $0.568(2.363)$ & $0.944(5.336)$ & $0.323(1.420)$ \\
\hline$\psi_{12}$ (t-value) & $0.313(1.518)$ & $-0.540(-1.963)$ & $0.263(2.246)$ \\
\hline$\psi_{21}$ (t-value) & $0.118(1.753)$ & $0.089(0.839)$ & $0.146(0.852)$ \\
\hline$\psi_{22}$ (t-value) & $1.104(19.075)$ & $0.877(5.289)$ & $1.020(13.424)$ \\
\hline$C A$ Granger causes $\triangle N C F^{* *}$ & Yes (0.149) & Yes $(0.068)$ & Yes $(0.022)$ \\
\hline Parameter $\beta$ & 0.792 & 0.905 & 0.547 \\
\hline Testing of $\mathrm{PIH}^{* * *}$ & reject $(0.061)$ & reject $(0.000)$ & not reject $(0.425)$ \\
\hline $\begin{array}{l}D \text { (t-value) } \\
\text { in } \Delta N C F \text { eq. }\end{array}$ & $-1,534(-3.084)$ & $-906(-2.225)$ & $-965(-2.703)$ \\
\hline $\begin{array}{l}D \text { (t-value) } \\
\text { in } C A \text { eq. }\end{array}$ & $-434(-3.119)$ & $-366(-1.494)$ & $-692(-2.640)$ \\
\hline
\end{tabular}

Note:

* Having small dimension samples, the KPSS test of stationarity was applied, not rejecting the null hypothesis (time-series is stationary) at least at the $1 \%$ level of significance.

** Probability in parentheses.

*** Wald test, $\mathrm{H}_{0}$ : PIH valid, probability in parentheses.

Source: author's own computations

In this case, the test of stationarity of $C A_{t}$ is superfluous: as $C A_{t}$ is a linear combination of $\triangle N C F_{t}$, its stationarity is sufficiently demonstrated.

Evidently, not all estimated parameters are significant but the improvement is considerable in comparison with the "interest rate being constant" versions. The poorest significance appears in the case of Austria. Of course, the time series describing the Austrian economy are available in sufficient length to provide more exact results. However, for the purpose of comparison with the other two economies, the availability of data concerning the Czech Republic and Slovakia was a limiting factor.

The Granger causality from $C A_{t}$ to $\triangle N C F_{t}$ is determined using the $\psi_{12}$ parameter. Its existence (although in the case of the Czech Republic at a significance level of only $14 \%$ ) speaks in favour of the assumption that the agents are endowed with prior information.

Although the interest rate is crucial for the eventual validity of the PIH and a manipulation with the interest rate variable may influence the other characteristics, using the variable interest rate it was necessary to drop the second relation in the pairs (22), (28), 
respectively. Parameter $\beta$ was computed as $\beta=1-\psi_{21} / \psi_{11}$. The Wald test of $\psi_{11} / \psi_{21}$ relates to possibility that $\beta=0$, hence the $\mathrm{PIH}$.

According to the results, the PIH is not rejected in the case of Austria; here it is necessary to note that the two parameters to be compared are not statistically significant. On the other hand, Pánková (2014) studied the countries from the point of view of PIH eventuality. Using the model proposed by Campbell and Mankiw (1990), constructed on the basis of Flavin (1981) and Hall (1978), it was found that 85\% of Austrian households consume according to the PIH in comparison to approximately 55\% of Czech households and $52 \%$ for Slovakia. The closeness of the consumption behaviour of Austrian households to the PIH explains lack of rejection of the PIH in these computations. The similarity of the positions of the Czech Republic and Slovakia is also apparent in the similar values of the $\beta$ parameter. The probability derived from the Wald test for the results of the Czech Republic permits very weak acceptance of the PIH, but this is unlikely to be economically correct; rather, the preferred argument is that the ESH holds in Slovakia as well as in the Czech Republic.

As for capital mobility, the Czech Republic and Slovakia show rather high correlations between national investments and savings:

Czech Republic

Slovakia
0.989

0.969

According to the Feldstein-Horioka hypothesis, this does not speak in favour of high capital mobility. Nevertheless, it does not relate to optimality which could be studied with the help of the above process. None of the economies in question have optimal capital mobility; the non-optimality of Austrian capital movements is weaker (smallest $\beta$ ) than that of the Czech Republic and Slovakia; their characteristics are again rather similar.

The influence of the financial crisis in the period 2008-2009 is apparent due to the significance of all (except for Slovakia) related parameters.

\section{Conclusions}

Theory underlying the verification of the PIH and eventually the ESH and the optimality of capital mobility in connection with the consumption smoothing of the current account has gradually been created and developed over the last three decades. The idea relating agent expectation to Granger causality, because the process of expectations may partially be studied using past values, enables the transformation of the optimal problem into the VAR model. Comparisons of predicted and actual values thus become relatively easy under the assumption that time series are sufficiently long. Otherwise, a technique testing the parameters of the estimated VAR model should be used, namely the approach chosen here.

All conclusions drawn in the previous paragraphs are weakened by the evidence of low statistical significance for some estimated parameters. Also, the economic and financial turbulence accompanying the period followed are reflected in the data series, especially in the unsustainable constancy of the interest rate. Moreover, the negative impact of the financial and economic crisis is beyond doubt. The unfavourable consequence may be that the results are not particularly robust. On the other hand, there are two supporting factors allowing the conclusions not to be rejected: i) the results correspond to a naïve expectation that the Czech Republic and Slovakia evince similar characteristics, which are apparently less favourable compared to Austria; ii) the results correspond to a study examining the PIH using another approach and a model implemented by the author. 


\section{References}

Adler, J. (2002). The Open Economy Excess Sensitivity Hypothesis: Theory and Swedish Evidence. Economics Working Papers No. 88. Available at: https://gupea.ub.gu.se/ bitstream/2077/2816/1/gunwpe0088.pdf

Araujo, J., Poplawski-Ribeiro, B. L. M., Zanna, L. F. (2013). Current Account Norms in Natural Resource Rich and Capital Scarce Economies. IMF Working Paper 13/80. DOI: 10.5089/9781484396032.001. Available at: http://www.imf.org/external/pubs/ft/ wp/2013/wp1380.pdf

Azariadis, C., Pissarides, C. A. (2004). Unemployment Dynamics with International Capital Mobility. Available at: http://personal.Ise.ac.uk/pissarid/papers/AP04.pdf

Campbell, J. Y., Mankiw, N. G. (1990). Permanent Income, Current Income and Consumption. Journal of Business \& Economic Statistics, 8(3), 265-279. DOI: 10.2307/1391964.

Feldstein, M., Horioka, C. (1980). Domestic Saving and International Capital Flows. Economic Journal, 90(358), 314-329. DOI: 10.2307/2231790.

Flavin, M. A. (1981). The Adjustment of Consumption to Changing Expectations about Future Income. The Journal of Political Economy, 89(5), 974-1009. DOI: 10.1086/261016.

Flavin, M. A. (1993). The Excess Smoothness of Consumption: Identification and Interpretation. Review of Economic Studies, 60(3), 651-666. DOI: 10.2307/2298129.

Frederick, S., Loewestein, G., O'Donoghue, T. (2002). Time Discounting and Time Preference: A Critical Review. Journal of Economic Literature, 40(2), 351-401. DOI: 10.1257/jel.40.2.351.

Gaglianone, W. P. (2004). Current Account and Capital Mobility Hypothesis: Evidence from the G-7. Available at: http://bibliotecadigital.fgv.br/dspace/bitstream/handle/10438/42/1845.pdf; jsessionid =F3DBA15A2DD225A0F9ED38AD01C46A86? sequence $=1$

Ghosh, A. R. (1995). International Capital Mobility amongst the Major Industrialised Countries: Too Little or Too Much? Economic Journal, 105(428), 107-128. DOI: 10.2307/2235322.

Hall, R. E. (1978). Stochastic Implications of the Life Cycle-Permanent Income Hypothesis: Theory and Evidence. Journal of Political Economy, 86(6), 971-987. DOI: 10.1086/260724.

Obstfeld, M., Rogoff, K. (1994). The Intertemporal Approach to the Current Account. NBER Working Paper No. 4893. DOI: 10.3386/w4893.

Rakovski, T. (2009). Consumption Smoothing Current Account and International Capital Mobility - Evidence from Time Series and Panel Data. McGill University. Available at: http://digitool. library.mcgill.ca/webclient/StreamGate? folder_id=0\&dvs=1385703336096 593

Pánková, V. (2014). Permanent Income Hypothesis in Visegrad Countries, Ekonomie + Management, 17(4), 20-29.

Sachs, J. (1982). The Current Account in the Macroeconomic Adjustment Process. Journal of Economics, 84(2), 147-159. DOI: 10.2307/3439631.

Younas, J. (2013). Role of Foreign Direct Investment in Estimating Capital Mobility: A Reappraisal of Feldstein-Horioka Puzzle. Available at: http://www.freit.org/WorkingPapers/Papers/ ForeignInvestment/FREIT106.pdf 